\title{
Introduction to Developmental Digital Technologies in Human History, Culture, and Well-Being
}

\author{
Carol D. Lee Colette Daiute $^{\mathrm{b}}$ \\ ${ }^{a}$ Northwestern University, Evanston, IL, USA; ${ }^{b}$ The Graduate Center, CUNY, \\ New York, NY, USA
}

This special issue is an outgrowth of the 2017 annual conference of the Jean Piaget Society. The theme of the conference was "Technologies and Human Development." Two special issues are being published from the conference presentations. The first is in Cognitive Development. The papers in Cognitive Development focus on interactive uses of digital media - learning games and games among online collectives to facilitate cognitive restructuring in individuals and collectives. By contrast, the papers in this special issue focus on technologies that facilitate restructuring of social interactions among people, and in so doing provide supports for influencing developmental issues around identity, around risk and resilience, and around building shared resources that support the development of communities, with special attention to digital technologies. Beyond the relatively vague idea of "context," these papers offer structural concepts that capture modes of social organization around the collective and individual uses of technologies. These include the constructs of "history" (Pea \& Cole, this vol.), "healthy learning ecosystem" (Pinkard, this vol.), "design-based learning" (Gutiérrez, Higgs, Lizárraga, \& Rivero, this vol.), and "computer-assisted interviews" (Lawrence, Kaplan, \& Dodds, this vol.).

From the original planning of the conference, we consciously conceptualized technologies in the broad sense to include, but not to be limited to, digital tools. We conceptualized technologies as human creations that facilitate structuring of opportunities to solve real-life problems. We view technologies as tools, influenced by Vygotsky (1978) and later interpretations by Wartofsky (1979) and Cole (1996), namely tools as both physical (e.g., hammers and shovels) and ideational (concepts, modes of reasoning). It is useful to note that language (whether oral or written) is a physical production, but whether oral or written, always embodies ideas and modes of reasoning. Across literatures, the terms "artifacts," "tools," and "technologies" are employed with shared and differing significations. Wartofsky articulated three levels of artifacts or tools: primary, secondary, and tertiary. As discussed by Cole (1996), primary arti-

\section{KARGER}

(c) 2019 S. Karger AG, Basel

E-Mail karger@karger.com www.karger.com/hde
Prof. Carol D. Lee

School of Education and Social Policy

Northwestern University, 2120 Campus Drive

Evanston, IL 60208 (USA)

E-Mail cdlee@ northwestern.edu 
facts are those used for purposes of production. Those identified by Wartofsky are physical in nature. However, Cole goes on to expand this category to include "words, writing instruments, telecommunications networks, and mythical cultural personages" (Cole, 1996, p. 121). Secondary artifacts "consist of representations of primary artifacts and modes of action using primary artifacts. Secondary artifacts play a central role in preserving and transmitting modes of action and belief. They include recipes, traditional beliefs, norms, constitutions, and the like" (Cole, 1996, p. 121). Tertiary artifacts "constitute a relatively autonomous world" (Wartofsky, 1979, p. 208). They include imaginative works of art that transport us into worlds beyond the ones we physically occupy and in so doing open opportunities to imagine the experiences of others and can influence how we see ourselves, others, and the world. In the article by Pea and Cole in this special issue, they go on to expand the idea of technologies to include not only the physical artifacts people create and employ to carry out tasks, but equally important physical and social organizations and routine practices entailed in the use of such artifacts. Across these conceptions of tools, artifacts, and technologies we extrapolate a few key propositions that we attribute to human technologies (tools, artifacts, and how they are used in practices):

- They embody human memory across time and space

- They facilitate the structuring of human physical, social, and emotional interactions and relationships

- They vary across time and space embedded within cultural communities of practice, with the aim of accomplishing fundamental tasks of human development but often in very different ways

- Technologies offer unique opportunities of facilitating the movement of knowledge across time and space and in so doing to influence fundamental shifts in human communities (e.g., note the influences of the introduction of the horse for purposes of transportation across civilizations, the evolution of the development of various forms of paper for writing, the invention of the printing press, the ubiquitous spread of digital tools such as cell phones today)

- There are bidirectional relationships between humans and the technologies they create and routinely use (e.g., humans create these technologies, and these technologies in turn influence the range of behaviors carried out and imagined by humans)

- Fundamental tasks of human development include minimally the following:

- Sustaining physical health and a sense of well-being

- Experiencing a sense of self-efficacy

- Building meaningful relationships that foster a sense of well-being and self-efficacy

- Learning to be adaptive to changing circumstances

- Learning to read the internal states of others

- Learning to read one's own internal states

We wrestle with these fundamental tasks from birth to death. However, how these tasks present themselves will differ substantively by where one is in the life course and what challenges one faces by virtue of the contexts one must navigate (Bowman, 1990; Spencer, 2006; Swanson, Edwards, \& Spencer, 2010). These contexts, most certainly in our historical moment, include categories that include experience of and ascriptions of group membership based on conceptions of race, ethnicity, class, gender, sexual orientation, nationality, religion, and political orientations as big fac- 
tors (Lee, 2009). How people, at different points across the life course, learn and come to wrestle, productively or unproductively, with these challenges is deeply affected by the range of supports available (Spencer, 2006). None of these categories of human categorization is deterministic of life course outcomes. People within and across these communities experience both risk and resilience. Of particular interest in the papers in this special issue are the ways that technologies, and in particular digital technologies, can play as resources for resilience in the face of societal challenges (Daiute, 2016). Our interest, as guest editors, is to situate these efforts to document these current uses of digital technologies as contributing to the field's fundamental investigations of how through conscious design of learning environments we can productively influence developmental outcomes for youth, especially youth from minoritized communities and those living in poverty.

Digital tools as technologies are both physical and conceptual (ideational). They are physical (e.g., computers, cell phones, the physical components of these machines, including the lines that carry signals underground or frequency waves traveling through the air) as well as conceptual (the computational programming that structures the underlying logic of operating systems, what one can think of as logical architecture of digital systems). These underlying architectures of digital tools range from programming that operates airplanes, traffic lights, and indeed in modern times that operates the majority of systems that structure almost every dimension of our lives. These also include the logic that underlies the array of genres of software that are available to help us do everything from ordering an Uber or Lyft, managing large databases, tutoring with personalized feedback from artificial intelligent systems, to creating virtual worlds we enter for a range of purposes. And then there are the ideational technologies that designers employ to bring into being the possibilities of problem solving and creation that such technologies make possible (e.g., programming for data mining, searching for information, conducting statistical modeling, structuring external representations in programs like Net Logo to examine dynamic systems). This then is the interesting web of technologies as we have broadly defined them that intentionally and sometimes unintentionally structure human life.

These structurings of possibilities help to shape our goals, our routine and nonroutine activities, and perhaps most important our social relations with one another (e.g., what we do together, what we seek to do together, and how we structure what occurs in joint activity). Thus, we argue that human development is and always has been intimately linked to our engagement with tools of all sorts, and that we are genetically predisposed by virtue of our evolution as a species to seek meaning as we navigate the physical world (Quartz \& Sejnowski, 2002). Such navigation has, as far as we can determine, always propelled us to strive to create tools, or as we chose to call them, technologies, that enable us to accomplish goals, where such technologies either involve the creation or adaptation of something beyond our bodies (or creating actions with our bodies) that allow us to accomplish a given task, that facilitate the accomplishment of goals and in the process open up new goals to pursue. Such technologies or tools may be used by individuals, but the spread of their use across individuals influences the development of communities, of shared practices, beliefs, and visions of possibilities for what we can do and be as humans. And while the focus of this special issue is on technologies employed by humans, with a particular focus on digital technologies, it is important to note that animals and plants also create and use tools, and these tools as technologies also help to shape possibilities of problem solv-

Developmental Digital Technologies in Human 
ing and the articulation of new goals for their species (Karpiński \& SzechyńskaHebda, 2010; Mancuso, 2017). We can thus think of tool creation and use, of technologies as tools of problem solving as a crucial lever of development.

Human learning and development are situated within complex systems entailing human physiological and psychological processes interacting with people's participation in cultural practices over time (Cole, 1996; Lee, 2010; Piaget, 2013; Rogoff, 2003; Vygotsky, 1981). A central resource in such complex systems are the inheritance of, the construction of, and the reconceptualizations of tools as resources for problem solving and the novel uses of complex genres that enable the enactment of systems, such as national narratives and policies (Daiute, 2014). As we have described, such tools can be physical or ideational/conceptual, and simultaneously physical and ideational/conceptual. As people interact with one another and with such tools as they engage in practices in routine and novel settings, these tools provide affordances for learning to carry out routine tasks and perhaps more important affordances for imagining new tasks and for learning how to carry out new tasks, indeed in new ways.

In human history, examples of such tools began as drawings (on walls and later on an array of medium), later as texts (oral genres, written genres with the advent of written literacies, on a variety of medium, eventually as print and now additionally as digital), and ritual practices (Derry \& Williams, 1960). These entailed symbol systems developed in culture and in turn themselves evolved culture. Over the history of humankind, the creation and evolution of new tools, which we are calling technologies, have served consequential roles in the reorganization of social, political, and economic relationships. Examples include the complex histories of the production of paper, the printing press, computational devices, computers, and the array of ubiquitous digital media that today influence the social organization of life across the planet. We argue that contemporary digital technologies need to be understood as part of the evolution of tool development in human communities.

We consciously recruited Roy Pea and Michael Cole to provide a historical overview of the evolution of tools created by humans and how these tools/technologies structured human activity, joint activity that opened new and unimagined possibilities of how humans interact with one another, what broader social, political, economic, and cultural goals they pursued. Their own histories as critical and creative pioneers in the field provide wisdom to help us interrogate how civilization moves forward (and backward) with contemporary uses of digital and symbolic technologies. Although social media existed only in its embryonic form via primitive "chat" routines and "meme" did not exist at all in their earlier works, theory and research by these two scholars remain beacons for contemporary research. This note in their article here remains a potent reminder:

Although tools are constituents of a technology, it is the way in which tools are combined and deployed as part of a sociocultural practice that is crucial to their consequences for the system into which they are inserted. (Pea \& Cole, this vol.)

Pea and Cole in "The Living Hand of the Past: The Role of Technology in Development" coordinate Piaget's (1973) and Vygotsky's (1978) theorizing through their joint attention to the mediation of development through interactions in the world with people engaged in routine social practices. The system of practices, including the tools deployed, constitutes a technology. When applied, for example, to the practices parents and caregivers structure to support the physical, social, emotional, and psy- 
chological well-being of children, Pea and Cole argue for what they call a technology of childrearing. We note that such technologies of childrearing do vary across cultural communities and across historical time frames (Rogoff, 2003). They trace the powerful role of the evolution of literacies across the millennia not only on the social, political, and economic organization of societies, but even on the anatomical development of the human brain. They continue this historical analysis with powerful illustrations of the exponential growth of what we think of now as digital technologies, in particular social media. Pea and Cole document the impacts of digital technologies and social media in particular on formal and informal institutions and the opportunities they have facilitated for unparalleled levels of participation in creative production, social engineering, and multitasking, while at the same time introducing unsettled paradoxes (e.g., how much time young children should spend with digital media; how and when to integrate digital tools into instruction in schools; do social media tools take away from face-to-face social interactions).

Digital technologies in our time structure so many of our ways of acting in the world, in ways so ubiquitous that they seem seamless, almost natural. Carol Lee just returned from giving a keynote address in China and was struck by the almost universal use of cell phones to order and pay for goods and services, to constantly be in communication with others, to organize virtual communities. As Colette Daiute has heard in interviews with asylum seekers in southern Italy, such virtual communities interact with life and death, a connection in the face of racist exclusion. Modernity is the universal force across virtually every nation state (albeit unevenly within nation states), embodied in powerful technologies that run transportation systems, information systems, health care systems, education systems, and an endless array of social activities that bind communities together. And perhaps most interesting, virtually all these systems are powered by digital technologies, their physical infrastructures and the conceptual architectures that enable them.

The papers in this special issue examine a range of consequential human developmental goals. By human developmental goals we mean foundational tasks with which we as humans at each stage of the life course must wrestle. These goals are foundational because they have evolved as part of our inheritance as a species. For example, we know that learning to read the internal states of other humans in relation to our ego-focused perception of needs (physical, emotional, social, psychological) is essential to human functioning (Flavell \& Miller, 1998; Kunda, 1999). Infants from birth pay more attention to human beings than objects (Meltzoff, 1988; Meltzoff \& Moore, 1977). Even before they gain language, infants wrestle with finding ways to communicate their needs to caregivers and others (Gopnik, Meltzoff, \& Kuhl, 1999). As part of their evolving social cognition, they come to learn that other people have ideas, beliefs, needs, and goals different from their own. This developmental stepping stone introduces new psychological challenges of learning to navigate more complex relations with others. These developmental processes of meaning making always entail processes of acquiring skill with tools or technologies that enable problem solving around goals: use of language, the ability through hand-eye and motor coordination to work with physical objects, acquiring skill in deploying ideas, beliefs, ways of reasoning that have social currency in their ecological niches. It is fascinating in this digital age to see how even very young children, without explicit instruction come to manipulate specialized tools on cell phones, to be mesmerized by digital media on screens, and to play digital games on cell phones, tablets, and computers.

Developmental Digital Technologies in Human History, Culture, and Well-Being
Human Development 2019;62:5-13 DOI: $10.1159 / 000496072$ 
Among the developmental goals whose exploration is facilitated by engagement with digital tools is imagining future possibilities (Oyserman, Bybee, \& Terry, 2006) and developing a sense of self-efficacy (Dweck, 1999). In "Freedom of Movement, Defining, Researching, and Designing the Components of a Healthy Learning Ecosystem" Pinkard demonstrates how the Digital Youth Network engaged youth, largely youth from minoritized communities living in poverty, in learning to develop computational literacies that allowed them to produce artifacts that critically examined their social, economic, and political realities and to pursue interests through access to resources that were typically not available in their communities. Lawrence, Kaplan and Dodds in "Computer Assisted Expressions of the Perspectives of Refugee Children in Resettlement" document how the underlying conceptual architecture of computer-assisted interviews promote children's autonomy in respectful and nonthreatening ways. They invited refugee children to express their perspectives about their sources of distress and help in resettlement. The tool was organized to provide supports in ways that promoted a sense of agency and control in telling what in their lives worried and helped them. The underlying architecture of the tool was structured to engage the child in conversation with the digital medium. It was designed in such a way as to employ language practices and idioms commonly used in the communities of these refugee children in Australia, recently having arrived from Syria and Iraq. The tool is developmentally responsive to the ages of the children, presenting them with a refugee story they can embody with their own experiences and perspectives. Gutiérrez, Higgs, Lizárraga, and Rivero in "Learning as Movement in Social DesignBased Experiments: Play as a Leading Activity" discuss the underlying propositions that inform social design-based experiments as a framework for the design of robust learning ecologies. The framework addresses learning ecologies from the assumption that human learning is not constrained to any one institutional niche. They document the unfolding of this framework in El Pueblo Mágico, an after-school STEMoriented 5th-dimension program (Cole \& the Distributed Literacy Consortium, 2006) in which youth from nondominant groups worked with university mentors to engage with digital tools for consequential learning situated in a world of play. The social organization of the after-school setting recruited diverse resources to coordinate for problem solving, ranging from repertoires from the children's everyday experiences at home and in the community to those of the university students who mentored. The underlying principles of the design (the design principles themselves a technology as we have discussed the idea of technologies) served to restructure power relations such that adults learned from children, and impacts spread from the after-school setting to the school and the community. This social design-based experiment illustrates our argument that technologies of human development include the full ecology of the uptake of tools embedded in systems of practice.

It is interesting to note across all three papers, sensemaking through narrative is a central genre enabled through the digital technologies used. Bruner (1990) and others (Daiute \& Nelson, 1997; Pinker, 2007; Sugiyama, 2001) have argued that narrative is a sensemaking tool used by human communities across time to make sense of phenomenon. Others have suggested we as humans have evolved this capacity for making narratives as a specialized human tool that has evolved across our history as a species. Research on narrative has demonstrated that young children, even before being explicitly taught, create stories whose structures embody characters engaged in goaldirected behaviors (Applebee, 1978; Trabasso \& Sperry, 1985). In the paper by Law- 
rence, Kaplan and Dodds, the tool is designed in such a way that children can express their perceptions of the worries experienced by animated characters in the digital story and their perceptions of their own worries. Children are asked also about their sources of help and support, a holistic design decision rooted in a conceptual tool around the value of understanding both sources of risk as well as resilience. One can thus think of narrative as a conceptual tool or technology that has been embodied in oral traditions, in texts, including visual genres and an array of digital medium. Across these papers we see how particular digital technologies when taken up in social practices can support the development of dispositions and epistemologies that value critical examination of the self and one's circumstances. It is important to note that across these papers, the uptake of these digital tools or technologies is social, embedded in joint activity.

Another theme across the papers addresses not only the developmental affordances of the tools or technologies themselves as they are taken up in activity, but equally interesting the design decisions employed in the construction of the technologies. Pinkard discusses not only the range of particular tools developed for use by youth in the work of the Digital Youth Network, but also the design considerations around how the tools could be made available across a wide audience in communities that typically do not have access to such technologies, beyond perhaps the ubiquitous cell phone. She documents the development over time of wrestlings around design decisions of how to make these technologies available, to whom, and under what circumstances. She documents the move from design decisions that would maximize opportunities within a single school site, but even then in ways that allowed and encouraged youth within that school to access the tools after school and from home. But then the design decisions expanded to wrestle with how to create incentives and supports for another set of digital technologies to recruit a broader audience of adolescents. These efforts and those that evolved over time then led to design decisions about building relationships with community partners and with the political leadership of the city at large and its constituent institutions (e.g., school system, library system, transit system). Because we have argued that technologies of development can be both physical and conceptual, it is useful to think about the shared concepts around the meaning of spaces, around definitions of equity, around shared and contested modes of reasoning that allow disparate points of view to intersect in ways that move decision making forward that those involved in the Digital Youth Network considered, developed, wrestled with, and engaged as technologies, as tools for problem solving. Evolving such conceptual technologies, if you will, allowed for expanding the model - Cities of Learning - across more than one city. In a similar vein, Lawrence, Kaplan, and Dodds made design decisions to build in affordances that would potentially moderate to some degree the challenges of children's new lives or reliving past traumas. This was done through the availability of telling their stories in the language or languages of their choice, the availability of a person who could assist them as needed through the process as well as the guiding supports built into the tool. We can then think of the system as both the affordances of the digital tool in tandem with the supports of the human interactions that constitute the technology system. Gutiérrez et al. take up the question of design decisions as technologies when they explore the idea of designing for social justice. The Social Design-Based Experiment framework itself is a tool for problem solving. It includes a set of core propositions - beliefs, dispositions, concepts, epistemologies around knowledge production - that we can

Developmental Digital Technologies in Human History, Culture, and Well-Being
Human Development 2019;62:5-13 DOI: $10.1159 / 000496072$ 
think of as technologies of development. Their aims are to support healthy human development in ways that honor communities.

The invited papers proposed for this special issue address a critical history of the consequences of the development of such technologies over time for human learning and development, as well as contemporary examples of how new digital technologies are playing critical roles in the reorganization of relationships with others and the self, and of how learning is distributed across people in unique culturally grounded settings. Such settings range from community organizations among Latinx populations to ecological relationships among city government, community organizations, and schools in low-income neighborhoods in a midwestern city with complex political, social, and economic challenges, to refugee youth living in challenging circumstances.

In each of these papers, the authors examine people's participation in activities that are part of evolving developmental niches (Super \& Harkness, 1986) - youth in families at particular stages in the life course where negotiating familial role relationships is in process; youth wrestling with issues of risk and resilience in the experience of societal level trauma; youth learning resources to support resilience as they engage in social play in virtual worlds; youth learning to tackle identity challenges using digital tools in the social organization of multi-aged settings. And in these developmental niches, digital technologies serve as resources, mediated by both the internal structures of the technologies as well as by how these are taken up through social interactions among people within the constraints and opportunities provided by particular settings. The empirical papers along with the introductory historical and theoretical overview together capture a complex conceptualization of the ways that digital technologies intersect with development.

\section{References}

Applebee, A. N. (1978). The child's concept of story: Ages two to seventeen. Chicago, IL: University of Chicago Press.

Bowman, P. (1990). Coping with provider role strain: Adaptive cultural resources among black husbandfathers. The Journal of Black Psychology, 16(2), 1-21. doi:10.1177/00957984900162002

Bruner, J. (1990). Acts of meaning. Cambridge, MA: Harvard University Press.

Cole, M. (1996). Cultural psychology, a once and future discipline. Cambridge, MA: Belknap Press.

Cole, M., \& The Distributed Literacy Consortium (Eds.) (2006). The Fifth Dimension: An after-school program built on diversity. New York, NY: Russell Sage.

Daiute, C. (2014). Narrative inquiry: A dynamic approach. Thousand Oaks, CA: Sage Publications.

Daiute, C. (2016). A relational approach to human development research and practice in 21 st century violence and displacement. Human Development, 59(2-3), 128-151. doi:10.1159/000448230

Daiute, C., \& Nelson, K. (1997). Making sense of the sense-making. Journal of Narrative and Life History, 7(1-4), 207-215. doi:10.1075/jnlh.7.25mak

Derry, T. K., \& Williams, T. I. (1960). A short history of technology from the earliest times to A.D. 1900 (Vol. 231). Oxford, UK: Oxford University Press. doi:10.1021/ed039pA244

Dweck, C. S. (1999). Self-theories: Their role in motivation, personality and development. Philadelphia, PA: The Psychology Press.

Flavell, J. H., \& Miller, P. H. (1998). Social cognition. In D. Kuhn \& R. Siegler (Eds.), Handbook of child psychology (Vol. 2, 5th ed., pp. 851-898). New York, NY: Wiley.

Gopnik, A., Meltzoff, A., \& Kuhl, P. (1999). The scientist in the crib: What early learning tells us about the mind. New York, NY: Harper Collins.

Karpiński, S., \& Szechyńska-Hebda, M. (2010). Secret life of plants: From memory to intelligence. Plant Signaling \& Behavior, 5(11), 1391-1394. doi:10.4161/psb.5.11.13243 
Kunda, Z. (1999). Social cognition: Making sense of people. Cambridge, MA: MIT Press.

Lee, C. D. (2009). Historical evolution of risk and equity: Interdisciplinary issues and critiques. Review of Research in Education, 33(1), 63-100. doi:10.3102/0091732X08328244

Lee, C. D. (2010). Soaring above the clouds, delving the ocean's depths: Understanding the ecologies of human learning and the challenge for education science. Educational Researcher, 39(9), 643-655. doi: 10.3102/0013189X10392139

Mancuso, S. (2017). The revolutionary genius of plants: A new understanding of plant intelligence and behavior. New York, NY: Atria Books.

Meltzoff, A. N. (1988). Imitation, objects, tools, and the rudiments of language in human ontogeny. $\mathrm{Hu}$ man Evolution, 3(1-2), 45-64. doi:10.1007/BF02436590

Meltzoff, A. N., \& Moore, M. K. (1977). Imitation of facial and manual gestures by human neonates. Science, 198(4312), 75-78. doi:10.1126/science.198.4312.75

Oyserman, D., Bybee, D., \& Terry, K. (2006). Possible selves and academic outcomes: How and when possible selves impel action. Journal of Personality and Social Psychology, 91(1), 188-204. doi:10.1037/00223514.91.1.188

Piaget, J. (1973). To understand is to invent: The future of education. New York, NY: Viking Press.

Piaget, J. (2013). Sociological studies. New York, NY: Routledge.

Pinker, S. (2007). The stuff of thought: Language as a window into human nature. London, UK: Penguin.

Quartz, S. R., \& Sejnowski, T. J. (2002). Liars, lovers, and heroes: What the new brain science reveals about how we become who we are. New York, NY: William Morrow.

Rogoff, B. (2003). The cultural nature of human development. New York, NY: Oxford University Press.

Spencer, M. B. (2006). Phenomenology and ecological systems theory: Development of diverse groups. In W. Damon \& R. M. Lerner (Eds.), Handbook of child psychology (Vol. 1, 6th ed., pp. 829-893). New York, NY: Wiley.

Sugiyama, M. S. (2001). Narrative theory and function: Why evolution matters. Philosophy and Literature, 25(2), 233-250. doi:10.1353/phl.2001.0035

Super, C., \& Harkness, S. (1986). The developmental niche: A conceptualization at the interface of child and culture. International Journal of Behavioral Development, 9(4), 545-569. doi: $10.1177 / 016502548600900409$

Swanson, D. P., Edwards, M. C., \& Spencer, M. B. (Eds.). (2010). Adolescence: Development during a global era. New York, NY: Elsevier.

Trabasso, T., \& Sperry, L. L. (1985). Causal relatedness and importance of story events. Journal of Memory and Language, 24(5), 595-611. doi:10.1016/0749-596X(85)90048-8

Vygotsky, L. (1978). Mind in society: The development of higher psychological processes. In M. Cole, V. John-Steiner, S. Scribner, \& E. Souberman (Eds.), Mind in society: The development of higher psychological processes. Cambridge, MA: Harvard University Press.

Vygotsky, L. (1981). The genesis of higher mental functions. In J. Wertsch (Ed.), The concept of activity in soviet psychology. Armonk, NY: Sharpe.

Wartofsky, M. (1979). Models: Representation and the scientific understanding. Dordrecht, the Netherlands: Reidel. doi:10.1007/978-94-009-9357-0

Developmental Digital Technologies in Human History, Culture, and Well-Being
Human Development 2019;62:5-13 DOI: $10.1159 / 000496072$ 